\title{
Comparison of Laryngoscopic View and Hemodynamic Changes with Flexitip McCoy and Macintosh Laryngoscope Blade in Predicted Easy and Difficult Airway
}

\author{
Zia Arshad, Haider Abbas, Jaishree Bogra, Sulekha Saxena*
}

Department of Anesthesiology, K G Medical University, Lucknow, India.

Email:*dr.sulekha2008@rediffmail.com

Received January $17^{\text {th }}, 2013$; revised March $15^{\text {th }}, 2013$; accepted June $20^{\text {th }}, 2013$

Copyright (C) 2013 Zia Arshad et al. This is an open access article distributed under the Creative Commons Attribution License, which permits unrestricted use, distribution, and reproduction in any medium, provided the original work is properly cited.

\begin{abstract}
Objective: To compare the laryngoscopic view and the hemodynamic changes by using flexitip McCoy laryngoscope with Macintosh laryngoscope. Method: Study design-Prospective randomized controlled study. A total of 220 patients were included in the study, Patients were allocated on the basis of their airway anatomy in to two groups, one is predicted easy group and the other one was predicted difficult airway group. Among each group, half of the patient intubation was performed with Macintosh blade and the other half was intubated with the help of McCoy blade. The airway prediction was done on the basis of Mallampati grade, thyromental distance, inter incisor gap, jaw protrusion and weight of the patient. Larygoscopic view and hemodynamic changes were recorded. Results: The change in pulse rate was significantly $(p=0.01)$ higher among the patients of Group B $(85.02 \pm 10.13)$ as compared to Group A (79.20 \pm 13.11) after induction in predicted easy patients. Similar observation was found for pulse rate after laryngoscopy among both predicted easy and difficult patients. The diastolic blood pressure was significantly $(\mathrm{p}=0.0001)$ higher in Group B $(86.34 \pm 9.78)$ than Group A (77.12 \pm 11.66$)$ after induction among predicted easy patients. However, diastolic blood pressure was significantly $(\mathrm{p}=0.0004)$ higher in Group A $(82.00 \pm 10.98)$ compared with Group B $(75.00 \pm 9.06)$ after induction among predicted difficult patients. The average time taken during laryngoscopy was insignificantly $(\mathrm{p}>0.05)$ higher in Group B $(13.90 \pm 5.95)$ compared with Group A (12.42 \pm 3.58$)$ among predicted easy patients. However, the time taken was significantly $(\mathrm{p}=0.0001)$ higher in Group A $(20.83 \pm 2.47)$ than Group B $(12.66 \pm 3.0)$ in predicted difficult patients. A majority of the patients of both the groups were in Grade I (Group A $=61.8 \%$, Group B $=81.8 \%$ ) followed by Grade II (Group A $=38.2 \%$, Group B $=18.2 \%$ ) among predicted easy patients. Conclusion: It was concluded that the McCoy blade may be an answer to Macintosh blade in difficult airway cases, but not the substitute of Macintosh blade in every cases. The McCoy blade improved laryngeal view in patients with limited neck extension.
\end{abstract}

Keywords: Macintosh Blade; McCoy Blade; Laryngoscopy; Airway

\section{Introduction}

Airway management is the task with which an anaesthesiologist encounters routinely. Adept airway management is an essential skill for an anaesthesiologist. Time to time different aids, devices and maneuvers are used to maintain the airway. A variety of laryngoscopes are in use to facilitate laryngoscopy and intubation. Many supraglottic devices are also available. Recently the fiberoptic bronchoscope has become a valuable tool for management of difficult airway.

${ }^{*}$ Corresponding author.
The Macintosh blade has been the most popular for laryngoscopy. Visualization of vocal cords for intubation was popularized by Sir Robert Macintosh and Sir Evan Magill in early 1940's. The flexitip McCoy laryngoscope was developed in the early 1990's as an aid to difficult intubation in adult patients. Differences have been reported in the view obtained with Macintosh laryngoscope blade and those with McCoy blade in its neutral position. McCoy blade in its neutral position produced a worse view than Macintosh1. However, it has also been reported that among the patients with initial poor laryngoscope view, the McCoy blade might enable faster and 
easier tracheal intubation. In other studies, the significant increase in heart rate and arterial blood pressure has been reported after laryngoscopy using the Macintosh blade, however, the use of McCoy blade has not been associated with any significant change in either heart rate or arterial blood pressure [2,3].

The present study was conducted to compare the difference of laryngoscopic view using McCoy's and Macintosh laryngoscope and haemodynamic changes resulting during laryngoscopy and intubation with the two blades in predicted easy and difficult airway.

\section{Material \& Method}

The study was conducted over a period of one year, including 220 patients who were admitted for surgery under general anaesthesia, requiring endotracheal intubation. All the patients selected were adults of either sex belonging to ASA (American Society of Anesthesiology) grade I and II. Patients were allocated in to two groups:

- Group A-Laryngoscopy performed with Macintosh in predicted easy and difficult airway $(n=55$ in each).

- Group B-Laryngoscopy performed with McCoy in predicted easy and predicted airway $(n=55$ in each).

Preoperatively the airway was assessed by using a scoring system including Mallampati grade, thyromental distance, Inter incisor gap and jaw protrusion. The weight of the patients were also recorded (Table 1).

The patients were given tab. Alprazolam $0.25-0.50$ $\mathrm{mg}$ night before the surgery. In the operating room, intra venous. line was secured and routine monitoring like heart rate, pulse rate, $\mathrm{ECG}, \mathrm{Spo}_{2}, \mathrm{ETCo}_{2}$ were attached. All patients were given inj. Glycopyrrolate $0.2 \mathrm{mg}$ i.v. Inj. Fentanyl $1-2 \mu \mathrm{g} / \mathrm{kg}$ body weight and inj. midazolam 1 $2 \mathrm{mg}$. Induction was done using inj. Propofol $1-2 \mathrm{mg} / \mathrm{kg}$ body weight. Inj. succinylcholine $2 \mathrm{mg} / \mathrm{kg}$ body weight was given to facilitate laryngoscopy and intubation. The pulse rate, blood pressure, means arterial pressure before and after laryngoscopy and time taken for laryngoscopy was recorded. The Cormak Lehane grading of laryngeal inlet was also noted.

Sample size calculation was based on a pilot study on 20 patients, with laryngeal view as the primary outcome. It was estimated that with a power of $80 \%$ at $5 \%$ sig-

Table 1. Operative airway scoring system.

\begin{tabular}{cccc}
\hline Score & $(0)$ & $(1)$ & $(2)$ \\
\hline Weight $(\mathrm{kg})$ & $<90$ & $90-110$ & $>110$ \\
Mallampati grade & $\mathrm{I}$ & $\mathrm{II}$ & $\mathrm{III}$ \\
Inter incisor gap & $>4 \mathrm{~cm}$ & $<4 \mathrm{~cm}$ & - \\
Thyromental distance & $>7 \mathrm{~cm}$ & $<7 \mathrm{~cm}$ & - \\
Jaw protrusion & Yes & No & \\
\hline
\end{tabular}

nificance, 50 patients in each group would be required. To allow the potential dropouts $(10 \%)$, we decided to recruit a total of 55 patients in each group in the present study. The results were represented as means $( \pm)$ and percentages. The chi-square test was used to compare dichotomous/categorical variables and unpaired t-test was used to compare the mean between the groups at baseline, after induction and laryngoscopy. The p-value $<0.05$ was considered as significant. All the analysis was carried out by using SPSS 16.0 version.

\section{Results}

The basic characteristics of the patients were insignificantly $(p>0.05)$ different between Group A and Group $\mathrm{B}$ in both predicted easy and predicted difficult patients, thus the groups were comparable (Table 2).

The pulse rate, blood pressure and arterial pressure were comparable at baseline in all groups. However, pulse rate was significantly $(p=0.01)$ higher among the patients of Group B $(85.02 \pm 10.13)$ as compared to Group A $(79.20 \pm 13.11)$ after induction in predicted easy patients. The pulse rate was significantly $(\mathrm{p}=$ 0.0001) higher in Group A (93.00 \pm 12.43$)$ than Group B $(83.00 \pm 13.78)$ after induction among predicted difficult patients. Similar observation was found for pulse rate after laryngoscopy among both predicted easy and difficult patients. There was no significant $(p>0.05)$ difference in the systolic blood pressure between Group A and Group B after induction and laryngoscopy in both predicted easy and difficult patients. However, the diastolic blood pressure was significantly $(p=0.0001)$ higher in Group B $(86.34 \pm 9.78)$ than Group A $(77.12 \pm$ 11.66) after induction among predicted easy patients. However, diastolic blood pressure was significantly $(\mathrm{p}=$ 0.0004) higher in Group A (82.00 \pm 10.98$)$ compared with Group B $(75.00 \pm 9.06)$ after induction among predicted difficult patients. The diastolic blood pressure was also significantly $(\mathrm{p}=0.009)$ higher in Group A $(90.5 \pm 15.54)$ compared with Group B $(83.00 \pm 13.74)$ after laryngoscopy among predicted difficult patients. No significant difference was observed in the mean arterial pressure value between Group A and Group B after induction and laryngoscopy among both predicted easy and difficult patients (Table 3).

The average time taken during laryngoscopy was insignificantly $(\mathrm{p}>0.05)$ higher in Group B (13.90 \pm 5.95) compared with Group A (12.42 \pm 3.58$)$ among predicted easy patients. However, the time taken was significantly $(\mathrm{p}=0.0001)$ higher in Group A $(20.83 \pm$ 2.47) than Group B $(12.66 \pm 3.0)$ in predicted difficult patients (Figure 1).

Majority of the patients of both the groups were in Grade I (Group A $=61.8 \%$, Group B $=81.8 \%$ ) followed 
Table 2. Basic characteristics of the patients.

\begin{tabular}{|c|c|c|c|c|c|c|c|c|c|c|}
\hline \multirow[t]{3}{*}{ Parameters } & \multicolumn{5}{|c|}{ Predicted easy } & \multicolumn{5}{|c|}{ Predicted difficult } \\
\hline & \multicolumn{2}{|c|}{$\begin{array}{l}\text { Group A } \\
(\mathrm{n}=55)\end{array}$} & \multicolumn{2}{|c|}{$\begin{array}{c}\text { Group B } \\
(\mathrm{n}=55)\end{array}$} & \multirow{2}{*}{ p-value } & \multicolumn{2}{|c|}{$\begin{array}{c}\text { Group A } \\
(\mathrm{n}=55)\end{array}$} & \multicolumn{2}{|c|}{$\begin{array}{c}\text { Group B } \\
(\mathrm{n}=55)\end{array}$} & \multirow{2}{*}{$\mathrm{p}$-value } \\
\hline & No. & $\%$ & No. & $\%$ & & No. & $\%$ & No. & $\%$ & \\
\hline \multicolumn{11}{|l|}{ Age in years } \\
\hline $20-40$ & 32 & 58.2 & 31 & 56.4 & \multirow{2}{*}{0.85} & 30 & 54.5 & 32 & 58.2 & \multirow[t]{2}{*}{0.70} \\
\hline $41-60$ & 23 & 41.8 & 24 & 43.6 & & 25 & 45.5 & 23 & 41.8 & \\
\hline Sex & & & & & & & 0.0 & & 0.0 & \\
\hline Male & 29 & 52.7 & 30 & 54.5 & \multirow[t]{2}{*}{0.84} & 31 & 56.4 & 30 & 54.5 & \multirow[t]{2}{*}{0.85} \\
\hline Female & 26 & 47.3 & 25 & 45.5 & & 24 & 43.6 & 25 & 45.5 & \\
\hline MPG & & & & & & & 0.0 & & 0.0 & \\
\hline II & 18 & 32.7 & 20 & 36.4 & \multirow{3}{*}{0.85} & 21 & 38.2 & 20 & 36.4 & \multirow[t]{3}{*}{0.58} \\
\hline III & 9 & 16.4 & 5 & 9.1 & & 4 & 7.3 & 3 & 5.5 & \\
\hline IV & 7 & 12.7 & 8 & 14.5 & & 10 & 18.2 & 9 & 16.4 & \\
\hline \multicolumn{11}{|l|}{ Thyromental distance } \\
\hline$<7$ & 0 & 0.0 & 0 & 0.0 & \multirow[t]{2}{*}{ NA } & 55 & 100.0 & 55 & 100.0 & \multirow[t]{2}{*}{ NA } \\
\hline$\geq 7$ & 55 & 100 & 55 & 43.3 & & 0 & 0.0 & 0 & 0.0 & \\
\hline \multicolumn{11}{|l|}{ Inter incisor gap } \\
\hline$<4$ & 0 & 0.0 & 0 & 0.0 & \multirow[t]{2}{*}{ NA } & 55 & 100.0 & 55 & 100.0 & \multirow[t]{2}{*}{ NA } \\
\hline$\geq 4$ & 55 & 100.0 & 55 & 43.3 & & 0 & 0.0 & 0 & 0.0 & \\
\hline Presence of jaw protrusion & 55 & 100.0 & 55 & 100.0 & NA & 55 & 100.0 & 55 & 100.0 & \\
\hline
\end{tabular}

Table 3. Comparison of pulse rate, blood pressure and mean arterial pressure between group A and B.

\begin{tabular}{|c|c|c|c|c|c|c|}
\hline & \multicolumn{3}{|c|}{ Predicted easy } & \multicolumn{3}{|c|}{ Predicted difficult } \\
\hline & $\begin{array}{c}\text { Group A } \\
(\mathrm{n}=55)\end{array}$ & $\begin{array}{c}\text { Group B } \\
(\mathrm{n}=55)\end{array}$ & p-value & $\begin{array}{l}\text { Group A } \\
(\mathrm{n}=55)\end{array}$ & $\begin{array}{c}\text { Group B } \\
(\mathrm{n}=55)\end{array}$ & $\mathrm{p}$-value \\
\hline \multicolumn{7}{|l|}{ Pulse rate } \\
\hline Baseline & $70.12 \pm 12.21$ & $74.23 \pm 9.23$ & 0.05 & $88.00 \pm 11.56$ & $86.00 \pm 9.88$ & 0.33 \\
\hline After induction & $79.20 \pm 13.11$ & $85.02 \pm 10.13$ & $0.01^{* *}$ & $93.00 \pm 12.43$ & $83.00 \pm 13.78$ & $0.0001^{*}$ \\
\hline After laryngoscopy & $86.34 \pm 11.12$ & $98.45 \pm 12.13$ & $0.0001^{* *}$ & $104.30 \pm 10.89$ & $97.00 \pm 11.78$ & $0.001^{*}$ \\
\hline \multicolumn{7}{|c|}{ Systolic blood pressure } \\
\hline Baseline & $126.00 \pm 22.45$ & $122.60 \pm 18.67$ & 0.39 & $128.70 \pm 23.79$ & $127.80 \pm 21.67$ & 0.84 \\
\hline After induction & $118.23 \pm 21.56$ & $115.80 \pm 20.40$ & 0.55 & $123.80 \pm 22.90$ & $123.00 \pm 24.78$ & 0.86 \\
\hline After laryngoscopy & $130.11 \pm 23.4$ & $127.50 \pm 19.43$ & 0.53 & $137.00 \pm 19.87$ & $143.00 \pm 22.45$ & 0.14 \\
\hline \multicolumn{7}{|c|}{ Diastolic blood pressure } \\
\hline After induction & $77.12 \pm 11.66$ & $86.34 \pm 9.78$ & $0.0001^{* *}$ & $82.00 \pm 10.98$ & $75.00 \pm 9.06$ & $0.0004^{*}$ \\
\hline After laryngoscopy & $86.77 \pm 13.23$ & $88.45 \pm 11.67$ & 0.48 & $90.5 \pm 15.54$ & $83.00 \pm 13.74$ & $0.009^{*}$ \\
\hline \multicolumn{7}{|c|}{ Mean arterial pressure value } \\
\hline Baseline & $94.60 \pm 22.45$ & $100.65 \pm 19.78$ & 0.14 & $96.30 \pm 20.97$ & $95.50 \pm 21.76$ & 0.84 \\
\hline After induction & $96.10 \pm 24.55$ & $90.43 \pm 23.34$ & 0.22 & $96.00 \pm 21.79$ & $91.00 \pm 19.20$ & 0.20 \\
\hline After laryngoscopy & $101.40 \pm 20.23$ & $99.11 \pm 18.66$ & 0.53 & $104.80 \pm 17.80$ & $103.00 \pm 20.90$ & 0.63 \\
\hline
\end{tabular}

"Unpaired t-test, ${ }^{* *}$ Significant. 
by Grade II (Group A $=38.2 \%$, Group B $=18.2 \%$ ) among predicted easy patients. However, Grade I was found in $78 \%$ patients of Group A among predicted easy and $70.9 \%$ in Group B among predicted difficult. The Grade II was observed to be $18.2 \%$ in Group A and $29.1 \%$ in Group B of predicted difficult patients. The Grade III was found in only Group A patients of predicted difficult (Figure 2).

\section{Discussion}

The McCoy levering blade differred from Macintosh blade in four respects, it has a hinged tip, a lever at proximal end, a spring loaded drum and a connecting shaft. The hinged tip blades controlled by a lever on the handle of laryngoscope allow elevation of epiglottis while decreasing over all movement. This unique design has shown two advantages over Macintosh, first the less force applied during laryngoscope and thus stress response is reduced. Secondly, difficult laryngoscopic visualization may be improved by lifting the epiglottis. This laryngoscope can improve the laryngeal view especially in the patients with neck fixed in neutral position or patients suspected cervical spine injury with cervical collar. Many types of laryngoscopes have been used for tracheal intubation [4-6]. In developing coun-

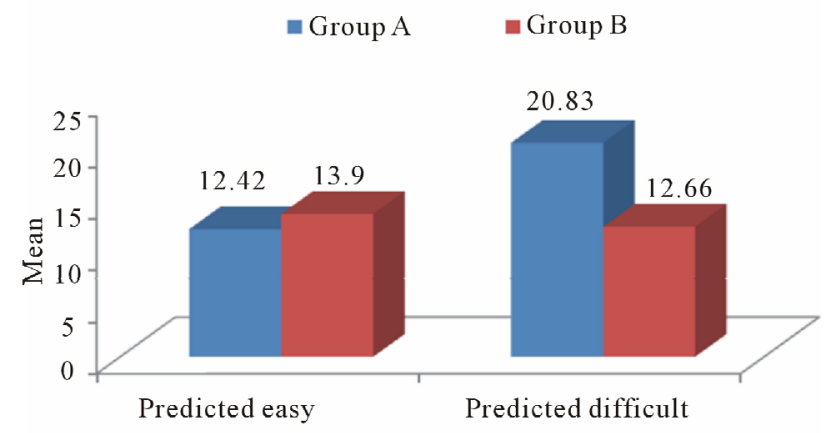

Figure 1. Average time taken during laryngoscopy.

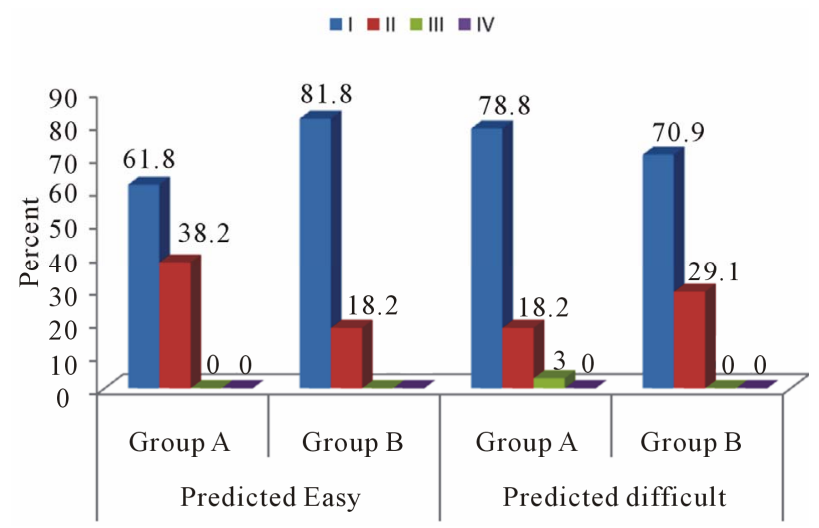

Figure 2. Incidence of cormak lehane grade. tries, direct laryngoscopy for tracheal intubation is usually performed with the Macintosh laryngoscope. However, direct laryngoscopy and intubation is a medical procedure that requires an experience [7]. Additionally, the novice's experience is one of the most successful intubation factors [8].

The present study was conducted to evaluate the difference of laryngoscopic view by using McCoy's and Macintosh laryngoscope and to compare haemodynamic changes resulting during laryngoscope and intubation with the two blades in predicted easy and difficult airway. The baseline characteristics of the patients were similar between both the groups which indicated that both the groups were comparable.

In the present study, the change in pulse rate was significantly different between sMacintosh McCoy's patients after induction and laryngoscope in both predicted easy and difficult airway. However, no significant difference was observed in the systolic blood pressure after induction and laryngoscope between the groups in both predicted easy and difficult airway. The diastolic blood pressure was significantly different after induction between the groups in both predicted easy and difficult airway. These findings differed to Nishiyama et al (1997) [3] in which they found that the stress response during laryngoscopy without intubation was significantly more in Macintosh than with McCoy laryngoscopy. However, in a study, the McCoy levering laryngoscopy improved laryngeal visualization even in patients whose neck could be extended [9]. It had been suggested that if the anaestheologist encountered an unexpected difficult laryngoscopy, MacCoy would be the better option as it proved easy, reliable and less time consuming. This was in contrast to present study. Here, time taken was less in MacCoy group in predicted easy airway and more in predicted difficult airway. The incidence of CormaK Lehane grade I was in $81.1 \%$ of the patients with McCoy blade in predicted easy airwy. It indicated that McCoy blade gave better visualization during laryngoscopy and thus, facilitated intubation.

Nevertheless the study has several limitations. We conducted our study on ASA I and II patients. In hypertensive patients, these responses might get exaggerated. These patients might then needed protection for hypertensive response even with McCoy laryngoscopy. It had been shown that the laryngoscopic view with McCoy laryngoscope suffered when neck was extended. Though Tuckey et al. (1996) [10] emphatically supported that once the laryngoscopic view with McCoy in neutral position was attained, there was no need for further manipulation. These manipulations might however add unnecessary haemodynamic upheavals, needing interventions. Familiarity and learning of correct use of McCoy 
laryngoscopy was fundamental as even with its lever in the "on position" one might get tempted to easily used it as Macintosh laryngoscopy. Other limitations included non-measurement of plasma levels of the induction agent.

\section{Conclusion}

It was concluded that the McCoy blade may be an answer to Macintosh blade in difficult airway cases, but not the substitute of Macintosh blade in every cases. The McCoy blade improved laryngeal view in patients with limited neck extension.

\section{REFERENCES}

[1] T. M. Cook and J. P. Tuckey, "A Comparison between the Macintosh and the McCoy Laryngoscope Blades," Anaesthesia, Vol. 51, No. 10, 1996, pp. 977-980. doi:10.1111/j.1365-2044.1996.tb14971.x

[2] E. P. McCoy, R. K. Mirakhur and B. V. McCloskey, “A Comparison of the Stress Response to Laryngoscopy. The Macintosh versus the McCoy Blade," Anaesthesia, Vol. 50, No. 11, 1995, pp. 943-946. doi:10.1111/j.1365-2044.1995.tb05924.x

[3] T. Nishiyama, T. Higashizawa, H. Bito, A. Konishi and T. Sakai, "Which Laryngoscope Is the Most Stressful in Laryngoscopy; Macintosh, Miller or McCoy?" Masui. The Japanese Journal of Anesthesiology, Vol. 46, No. 11, 1997, pp. 1519-1524.
[4] J. B. Li, Y. C. Xiong, X. L. Wang, X. H. Fan, Y. Li and H. $\mathrm{Xu}$, et al., "An Evaluation of the Truview EVO2 Laryngoscope," Anaesthesia, Vol. 62, No. 9, 2007, pp. 940-943. doi:10.1111/j.1365-2044.2007.05182.x

[5] M. Barak, P. Philipchuck, P. Abecassis and Y. Katz, "A Comparison of the Truview Blade with the Macintosh Blade in Adult Patients," Anaesthesia, Vol. 62, No. 8, 2007, pp. 827-833.

doi:10.1111/j.1365-2044.2007.05143.x

[6] G. L. Samsoon and J. R Young, "Difficult Tracheal Intubation: A Retrospective Study," Anaesthesia, Vol. 42, No. 5, 1987, pp. 487-490. doi:10.1111/j.1365-2044.1987.tb04039.x

[7] T. M. Cook, R. M. Levitan, A. Ochroch and J. Hollander, "POGO Score," Canadian Journal of Anaesthesia, Vol. 47, No. 5, 2000, pp. 477-478. doi:10.1007/BF03018985

[8] I. Singh, A. Khaund and A. Gupta, "Evaluation of Truview EVO2 Laryngoscope in Anticipated Difficult Intubation: A Comparison to Macintosh Laryngoscope," Indian Journal of Anaesthesia, Vol. 53, No. 2, 2009, pp. 164-168.

[9] T. Uchida, Y. Hicawa, Y. Saito and K. Yasuda, "The McCoy Levering Laryngoscope in Patients with Limited Neck Extension," Canadian Journal of Anaesthesia, Vol. 44, No. 6, 1997, pp. 674-676. doi:10.1007/BF03015455

[10] J. P. Tuckey, T. M. Cook and C. A. Rander, "Forum. An Evaluation of the Levering Laryngoscope," Anaesthesia, Vol. 51, No. 1, 1996, pp. 71-73. 